\title{
Surface Charge Accumulation of Particles Containing Radionuclides in Open Air
}

\author{
Yong-ha Kim, ${ }^{1}$ Sotira Yiacoumi, ${ }^{1, *}$ and Costas Tsouris ${ }^{1,2}$ \\ ${ }^{1}$ Georgia Institute of Technology, Atlanta, Georgia 30332-0373, United States \\ ${ }^{2}$ Oak Ridge National Laboratory, Oak Ridge, Tennessee 37831-6181, United States \\ *Corresponding author: E-mail sotira.yiacoumi@ce.gatech.edu
}

Submitted for publication in

Journal of Environmental Radioactivity

December 2014

Revised manuscript submitted in February 2015

Notice: This manuscript has been authored by UT-Battelle, LLC under Contract No. DE-AC0500OR22725 with the US Department of Energy. The United States Government retains and the publisher, by accepting the article for publication, acknowledges that the United States Government retains a non-exclusive, paid-up, irrevocable, world-wide license to publish or reproduce the published form of this manuscript, or allow others to do so, for United States Government purposes. The Department of Energy will provide public access to these results of federally sponsored research in accordance with the DOE Public Access Plan (http://energy.gov/downloads/doe-public-access-plan). 


\section{Graphical Abstract}

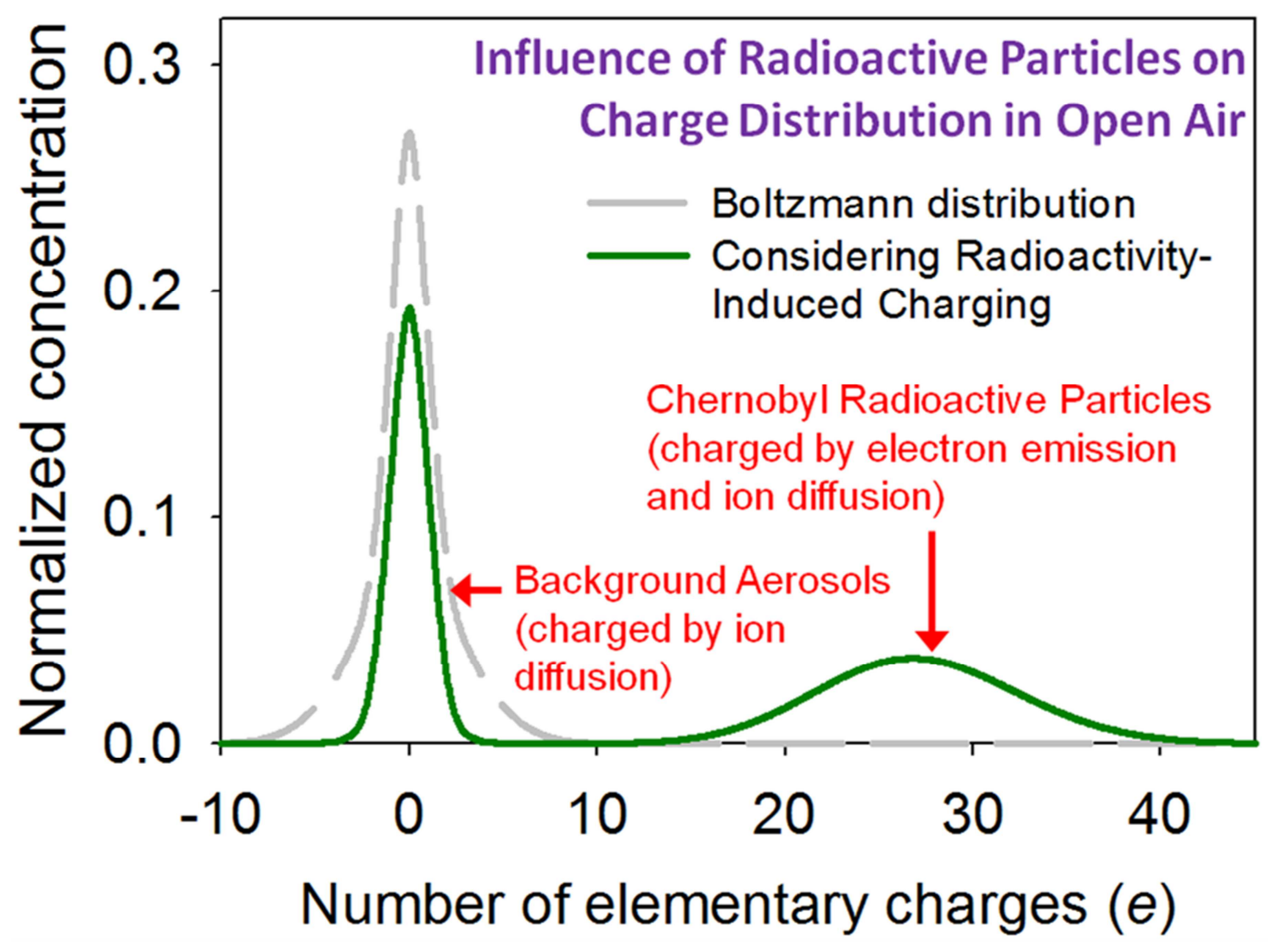




\section{Surface Charge Accumulation of Particles Containing Radionuclides in Open Air}

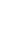

ABSTRACT. Radioactivity can induce charge accumulation on radioactive particles. However, electrostatic interactions caused by radioactivity are typically neglected in transport modeling of radioactive plumes because it is assumed that ionizing radiation leads to charge neutralization.

The assumption that electrostatic interactions caused by radioactivity are negligible is evaluated here by examining charge accumulation and neutralization on particles containing radionuclides in open air. A charge-balance model is employed to predict charge accumulation on radioactive particles. It is shown that particles containing short-lived radionuclides can be charged with multiple elementary charges through radioactive decay. The presence of radioactive particles can significantly modify the particle charge distribution in open air and yield an asymmetric bimodal charge distribution, suggesting that strong electrostatic particle interactions may occur during short- and long-range transport of radioactive particles. Possible effects of transported radioactive particles on electrical properties of the local atmosphere are reported. The study offers insight into transport characteristics of airborne radionuclides. Results are useful in atmospheric transport modeling of radioactive plumes. 


\section{Introduction}

Atmospheric dispersion of particles containing radionuclides may cause environmental and public health problems. The Chernobyl and Fukushima accidents led to radioactive contamination in many regions through transport and deposition of radionuclides (Chesser et al., 2004; Ooe et al., 1988; Pöllänen et al., 1997; Parache et al., 2011). Some areas may be contaminated for a long period of time due to the presence of long-lived radionuclides [e.g., ${ }^{137}$ Cs (Yoshenko et al., 2006a, 2006b)]. Thus, accurate prediction of transport of radioactive particles is needed from the beginning of a nuclear event in order to reduce uncertainty in our evaluations of environmental and health risks.

Modeling efforts have been made to predict transport of airborne radionuclides (ApSimon et al., 1989; Lee and Feichter, 1995; Rehfeld and Heimann, 1995; Pöllänen et al., 1997). However, discrepancies between theory and observations have been reported. For the Chernobyl case, large radioactive particles, which in theory should settle quickly, were transported to areas far away from the site of the accident (Lujanienè et al., 2009; Pöllänen et al., 1997). Predictions that did not follow well the observations were also reported for other cases of radioactivity transport (ApSimon et al., 1989; Lee and Feichter, 1995; Rehfeld and Heimann, 1995). These discrepancies emphasize the need to improve predictive modeling of radioactivity transport.

The nature of particulates in radioactive plumes plays a major role in radioactivity transport (Pöllänen et al., 1997). So far, it has been assumed that, because radionuclides are typically carried by background aerosols (Kaneyasu et al., 2012), radioactive particles behave similarly to atmospheric particles, whose electrostatic surface interactions are neglected (Seinfeld and Pandis, 2006). It has been shown, however, that radioactive particles can be strongly charged (Clement 
and Harrison, 1992; Gensdarmes et al., 2001; Kim et al., 2014; Kweon et al., 2013; Reed et al., 1977; Walker et al, 2010; Yeh et al., 1976); therefore, the assumption of neglecting electrostatic interactions may cause inaccuracies in predicting transport of radioactive particles. Nevertheless, the assumption has been used in many cases with the explanation that the presence of ionizing radiation induces charge neutralization of particles in open air (Greenfield, 1956, 1957). For example, Greenfield (1957) employed this assumption and found that the wet scavenging rate of radioactive particles can significantly decrease for a particle size range of $0.1-1 \mu \mathrm{m}$. This size range is typically called the Greenfield gap (Seinfeld and Pandis, 2006; Shaw, 1986). To reduce uncertainty in predictive modeling of radioactivity transport, there is a need to investigate whether radioactive particles can be charged in open air in order to evaluate the convenient assumption of negligible electrostatic interactions. In particular, although radioactive particles typically contain mixtures of radionuclides (Cuddihy et al., 1989; Devell et al., 1986; Kaneyasu et al., 2012; Kauppinen et al., 1986; Pöllänen et al., 1997), little information has been reported about ionizing radiation and particle charging under such conditions. Thus, this study examines charge accumulation and neutralization on the surface of particles containing various radionuclides in open air, under realistic conditions, to assess the importance of electrostatic interactions caused by radioactivity.

\section{Methodology}

\subsection{Characteristics of Radioactive Particles}

Various radionuclides (e.g., ${ }^{99} \mathrm{Mo},{ }^{103} \mathrm{Ru},{ }^{106} \mathrm{Ru},{ }^{131} \mathrm{I},{ }^{132} \mathrm{Te},{ }^{134} \mathrm{Cs}$, and ${ }^{137} \mathrm{Cs}$ ) were found in particles released from the Chernobyl and Fukushima accidents (Cuddihy et al., 1989; Devell et al., 1986; Kaneyasu et al., 2012; Kauppinen et al., 1986; Pöllänen et al., 1997). The radioactivity 
67

80

$\eta$ of individual particles containing radionuclides can be given by the number of radioactive atoms and decay constant $\lambda$ :

$$
\eta_{k}=\sum_{i} \eta_{k, i}=\sum_{i} \frac{m_{k} N_{A} f_{i}}{\mu_{\text {mean }}} \lambda_{i}
$$

where $m_{k}$ is the mass of size $k$ particles, $N_{A}$ is Avogadro's number, $f_{i}$ is the mole fraction of a radionuclide $i$ and $\mu_{\text {mean }}$ is the mean atomic weight.

For beta decay, radionuclides emit electrons with kinetic energy $T$. Energy deposition by the emitted electrons causes atomic electron ejection from gas molecules in air, thereby generating ion pairs. The mean number of ion pairs produced per decay $I$ (i.e., ionization rate coefficient) can be estimated using the linear energy transfer (LET) equation (Huizenga and Storchi, 1989; ICRU, 1984; Tomé and Palta, 1998) and the additivity rule (Bragg and Kleeman, 1905):

$$
I_{i}=\left[\sum_{l} f_{l}\left(\frac{1}{\rho} \frac{-d E}{d x}\right)_{\Delta, l}\right] \frac{\delta_{i}}{w_{\text {air }}}
$$

where $f_{l}$ is the weight fraction of an element $l, \rho$ is the air density, $\Delta$ is the cut-off energy, $\delta$ is the path length of electrons, and $w_{\text {air }}$ is the ionization potential. LET, $(-d E / d x)_{\downarrow, l}$, represents the mean energy loss of energetic electrons during their movement and involves energy transfer to air molecules. LET can be given as

$$
\left(\frac{1}{\rho} \frac{-d E}{d x}\right)_{\Delta, l}=\frac{2 \pi r_{e}^{2} m_{e} c^{2}}{\beta^{2}} \frac{Z}{u A}\left[\ln \left(\frac{T}{I_{\text {excitation }}}\right)^{2}+\ln \left(1+\frac{\tau}{2}\right)+G(\tau, \eta)\right]
$$


where $r_{e}$ is the classical electron radius, $m_{e}$ is the rest mass of the electron, $c$ is the velocity of light, $\beta$ is the ratio of electron velocity to the velocity of light, $Z$ is the atomic number, $u$ is the atomic mass unit, $A$ is the atomic weight, $I_{\text {excitation }}$ is the mean excitation energy of the element, $G$ is the auxiliary function (Tomé and Palta, 1998), $\tau=T / m_{e} c^{2}$ and $\eta=\Delta / T$. In equation 3, the sum of the three terms in square brackets on the right-hand side (RHS) represents the dimensionless stopping number for elements (Seltzer and Berger, 1982). In particular, the last term restricts the amount of transferred energy up to $\Delta$.

We assumed that air consists of $\mathrm{N}_{2}, \mathrm{O}_{2}, \mathrm{CO}_{2}$, and $\mathrm{Ar}$ and that the weight fraction of $\mathrm{N}, \mathrm{O}, \mathrm{C}$, and Ar is comparable to the dry air around sea level. To secure validity of eq 3 , the binding energies of atomic electrons should be smaller than $\Delta$. Similarly to ICRU (1984) and Tomé and Palta (1998), it was assumed that $\Delta=1 \mathrm{keV}$ for $\mathrm{N}, \mathrm{O}$, and $\mathrm{C}$ and $\Delta=10 \mathrm{keV}$ for Ar, which can be greater than the binding energies of atomic electrons in $\mathrm{K}$ - and L-shells of the elements. Ionizing radiation caused by beta decay can polarize elements, which can influence LET. However, this effect is negligible for electrons with $T \leq 10 \mathrm{MeV}$ (ICRU, 1984). $I_{\text {excitation }}$ of the elements can be obtained from the empirical formula (Marmier and Sheldon, 1969). For beta decay, $w_{a i r}=34 \mathrm{eV}$ (Whyte, 1963).

The path length of energetic electrons depends on their kinetic energy. Because it is difficult to predict the tortuous path of energetic electrons, the mean path length of the electrons was estimated using the semi-empirical range-energy relationship given by Katz and Penfold (1952):

$R=0.412 T^{1.265-0.0954 \ln T} \quad(0.01<T \leq 2.5 \mathrm{MeV})$ 
where $R$ is the range of electrons in $\mathrm{g} / \mathrm{cm}^{2}$. In contrast to alpha decay, beta decay exhibits a continuous energy distribution because of the creation of antineutrinos. In this study, the ionization coefficients of radionuclides and the mean path length of energetic electrons were estimated using the mean value of the energy distribution, $E_{\text {mean }}$. Equations 1-2 provide the number of electrons emitted and ion pairs produced by beta decay of radionuclides.

\subsection{Charge Balance Model}

Electron emission and diffusion of positive and negative ions induce charge accumulation and neutralization on radioactive particles (Kim et al., 2014). Electron emission refers to the selfcharging mechanism, while ion diffusion corresponds to the diffusion-charging mechanism. For beta decay, the net charge accumulation rate on radioactive particles is given by:

$$
\frac{d J}{d t}=\eta+\beta_{J}^{+} n_{+}-\beta_{J}^{-} n_{-},
$$

where $J$ is the charge number, $\beta_{J}^{ \pm}$is the ion-particle attachment coefficient, $n_{ \pm}$is the ion concentration, and $t$ is time. Clement and Harrison (1992) extended eq 5 to investigate the charging of monodispersed particles containing single radionuclides. Based on the work of Clement and Harrison, a sectional approach can give the charge distribution of polydispersed particles containing various radionuclides as:

$$
\frac{d N_{k j}}{d t}=\eta_{k, j-1} N_{k, j-1}-\eta_{k, j} N_{k, j}+\beta_{k, j-1}^{+} n_{+} N_{k, j-1}-\beta_{k, j}^{+} n_{+} N_{k, j}+\beta_{k, j+1}^{-} n_{-} N_{k, j+1}-\beta_{k, j}^{-} n_{-} N_{k, j},
$$

$$
\text { where } N_{k j} \text { is the number concentration of radioactive particles of size } k \text { and charge } j \text {. In eq } 6 \text {, the }
$$
first two terms on the RHS represent the charge accumulation rate by the self-charging 
mechanism and the remaining terms account for the charge accumulation rate by the diffusioncharging mechanism. The ion-particle attachment, ion-ion recombination, ionization, and electron emission can influence the ion concentration (Clement and Harrison, 1992; Renard et al., 2013), through the following equations:

$\frac{d n_{+}}{d t}=-n_{+} \sum_{k} \sum_{j} \beta_{k, j}^{+} N_{k, j}-\alpha_{r c} n_{+} n_{-}+q$,

$\frac{d n_{-}}{d t}=-n_{-} \sum_{k} \sum_{j} \beta_{k, j}^{-} N_{k, j}-\alpha_{r c} n_{+} n_{-}+q+\sum_{k} \sum_{j} N_{k, j} \eta_{k, j}$

where $\alpha_{r c}$ is the recombination coefficient and $q$ is the bipolar ion production rate. In eqs 7 and 8 , the first two terms on the RHS represent ion loss through ion-particle attachment and ion-ion recombination. The third term represents ion production by beta radiation, as well as other ion sources, and can be obtained using

$q=\sum_{i} q_{I, i}+q_{b}$

where $q_{I, i}$ and $q_{b}$ are the bipolar ion production rates of beta-emitting radionuclides and other ion sources, respectively. $q_{I, i}$ can be calculated by multiplying the number of electrons emitted per unit time with their ionization rate coefficient. The last term of eq 8 accounts for the emitted electrons. Effects of each radionuclide on charge accumulation are included using $\eta$ and $q_{I, i}$. Eqs 6-8, without radioactivity terms, can be valid in predicting electrification phenomena of aerosols in the upper troposphere and stratosphere (Renard et al., 2013). In this study, the ionparticle attachment coefficient in the charge balance equation was estimated according to Harrison and Carslaw (2003). 


\subsection{Experimental Data}

141 Experimental data from the literature were used to validate the charge balance model and ionization rate coefficient (Table 1). The charge distribution of ${ }^{137} \mathrm{Cs}$ particles was measured as a function of $\eta$ and $I$. The charge accumulation of ${ }^{198} \mathrm{Au}$ particles was investigated as a function of $\eta$. The experiments were carried out in cylindrical tubes. Under such condition, the mean path length of electrons can be estimated as a function of the tube diameter, $d_{t u b e}$ on the basis of the criteria of Clement and Harrison (1992) and Gensdarmes et al. (2001): if $\delta_{i, \text { mean }}<d_{\text {tube }}, \delta_{i}=$ $(\pi / 4) d_{\text {tube }}$, while $\delta_{i}=d_{\text {tube }}$ if $\delta_{i, \text { mean }}>d_{\text {tube }}$.

Table 1. Experimental observations on charging of beta-emitting radioactive particles

\begin{tabular}{|c|c|c|c|c|c|c|c|}
\hline \multirow{2}{*}{$\begin{array}{l}\text { Radionuclide } \\
\text { Case number }\end{array}$} & \multicolumn{4}{|c|}{${ }^{137} \mathrm{Cs}$} & \multicolumn{3}{|c|}{${ }^{198} \mathrm{Au}$} \\
\hline & 1 & 2 & 3 & 4 & 5 & 6 & 7 \\
\hline Radioactivity $\eta(\mathrm{mBq})$ & 12.8 & 3.2 & 12.8 & 3.2 & 470 & 210 & 77 \\
\hline Ionization rate coefficient $I$ & 52 & 4,395 & 52 & 4,395 & - & - & - \\
\hline Particle diameter $(\mu \mathrm{m})$ & 0.82 & 0.82 & 1.05 & 1.05 & 0.53 & 0.53 & 0.53 \\
\hline Tube diameter $(\mathrm{cm})$ & 0.6 & 40 & 0.6 & 40 & 1.5 & 1.5 & 1.5 \\
\hline \multirow{2}{*}{$\begin{array}{ll}\text { Ion mobility: } & \text { Positive ion } \\
\left(\mathrm{cm}^{2} \mathrm{~V}^{-1} \mathrm{~s}^{-1}\right) & \text { Negative ion }\end{array}$} & \multicolumn{4}{|c|}{1.19} & \multicolumn{3}{|c|}{1.2} \\
\hline & \multicolumn{4}{|c|}{1.54} & \multicolumn{3}{|c|}{1.2} \\
\hline References & \multicolumn{4}{|c|}{ Gensdarmes et al. (2001) } & \multicolumn{3}{|c|}{$\begin{array}{c}\text { Clement and Harrison (1992) } \\
\text { Yeh et al. (1976) }\end{array}$} \\
\hline
\end{tabular}

mBq: milliBecquerels 


\section{Results and Discussion}

153

\subsection{Ionization Rate Coefficient}

The ionization rate coefficient $I$ of radionuclides was estimated using LET (eq 2) and evaluated employing the charge balance model and experimental data (Cases 1-7). For comparison, $I$ was also estimated from a typical approach using the Beer-Lambert (BL) law (Clement and Harrison, 1992; Cooper and Reist, 1973; Gensdarmes et al., 2001). Hereafter, we refer to estimation by the LET or BL approach, respectively. Note that the BL approach employed in this study includes the empirical formula for air (Martin, 2000), while previous studies have used that obtained for aluminium (Clement and Harrison, 1992; Cooper and Reist, 1973; Gensdarmes et al., 2001).

Figure 1(a) shows the charge accumulation rates for Case 1 . The ionization rate coefficient was estimated as $I_{L E T}=29$ by the LET approach and $I_{B L}=126$ by the BL approach. Both approaches predicted that ${ }^{137} \mathrm{Cs}$ particles initially accumulated positive charge, which neutralized the negative surface charge assumed initially based on the experiments by Gensdarmes et al. (2001). However, the results with $I_{L E T}$ were closer to the experimental data than those with $I_{B L}$. The discrepancy resulted from the difference in the ion concentration caused by ionization. For the case with $I_{L E T}$, the ion concentration in the system increased more slowly and was lower than that estimated by $I_{B L}$, causing the particles to accumulate more positive charges through the selfcharging mechanism until the diffusion-charging mechanism was strong enough to counterbalance the surface charge. As shown in Table 1, the mobility of negative ions is greater than that of positive ions, and this is the reason that the diffusion-charging mechanism neutralizes positive charge added by the self-charging mechanism. 

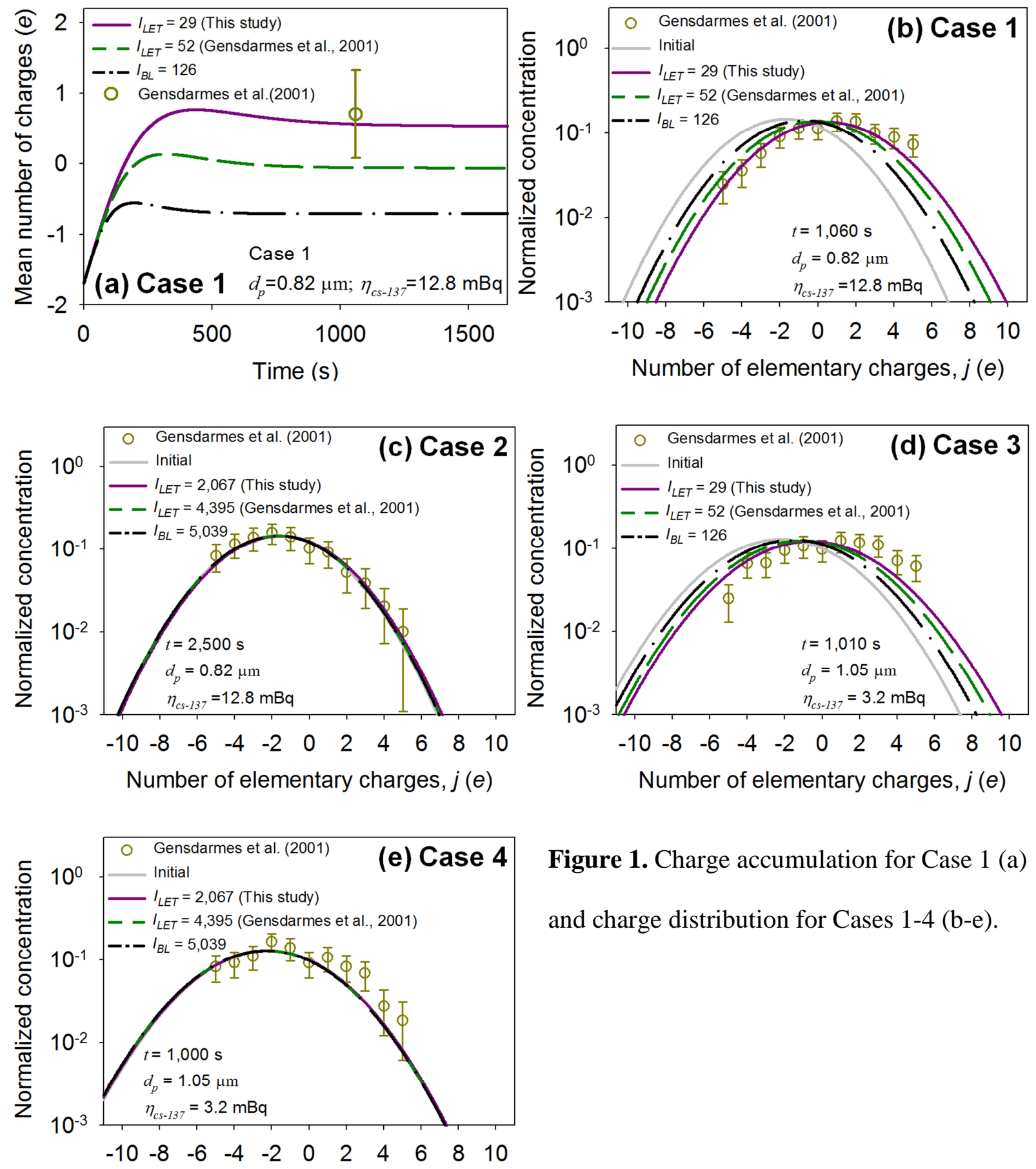

Figure 1. Charge accumulation for Case 1 (a) and charge distribution for Cases 1-4 (b-e).

Number of elementary charges, $j(e)$

176 The $I_{L E T}$ value of this study was different than that of Gensdarmes et al. (2001) due to the

177 differences in determining (1) the mean kinetic energy of electrons and (2) the estimation method 
to obtain LET. To compute the amount of energy transferred to air molecules, we employed the mean kinetic energy obtained from the beta spectrum of ${ }^{137} \mathrm{Cs}\left[E_{\text {mean }}=0.192 \mathrm{MeV}\right.$ (Mantel, 1972)], while Gensdarmes et al. (2001) assumed that the mean kinetic energy is one fourth of the maximum kinetic energy $\left(E_{\text {mean }}=0.128 \mathrm{MeV}\right)$. For ${ }^{137} \mathrm{Cs}$, a lower $E$ provides a higher value for LET, thereby increasing its ionization rate coefficient. In this study, LET was estimated using the restricted LET formula with the cut-off energy, while Gensdarmes et al. (2001) obtained LET from a chart in Joffre (1963) without providing specific assumptions. Nevertheless, the LET approach of this study predicted the charge accumulation rates for Cases 1 and 3 more accurately than the LET approach described in Gensdarmes et al. (2001) [Figure 1(b) and 1(d)].

For Cases 2 and 4, the results of both approaches agreed well with the measurements [Figure 1(c) and (e)], but the LET approach forecasted more precisely the charge accumulation behavior of the ${ }^{198} \mathrm{Au}$ particles (Cases 5 to 7) (Figure 2). Compared to Reed et al. (1977) and Clement and Harrison (1992), the discrepancy in the predictions for Cases 5 - 7 results mainly from employing different ion mobilities and ionization rate coefficients. These results suggest that the LET approach employed in this study can reliably estimate ionization rate coefficients of radionuclides to predict charge accumulation on radioactive particles.

\subsection{Charge Accumulation on Particles Containing Radionuclides}

Charge accumulation on particles containing radionuclides was investigated using the charge balance model with eqs 1-3 under the experimental conditions of Cases 1-4. The mole fraction of ${ }^{137} \mathrm{Cs}$ contained in the particles was estimated using eq 1 . It was assumed that (i) various shortlived and long-lived radionuclides are added to the ${ }^{137} \mathrm{Cs}$ particles, (ii) the mole fraction of added radionuclides equals that of ${ }^{137} \mathrm{Cs}$, and (iii) their radioactivity is constant because of short charge accumulation time. 


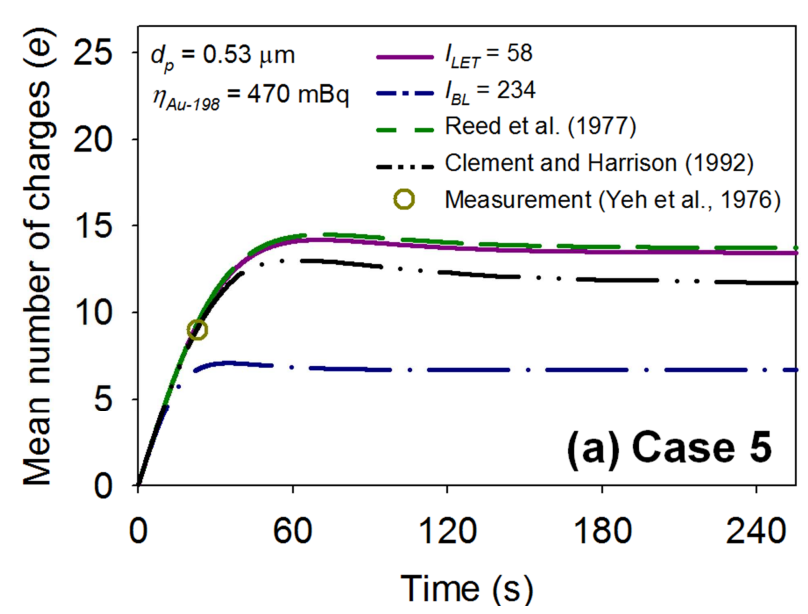

201

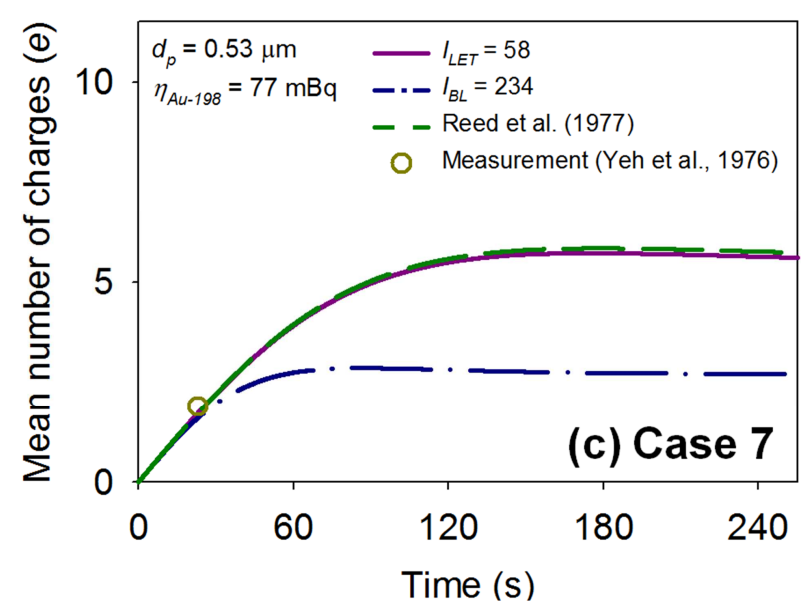

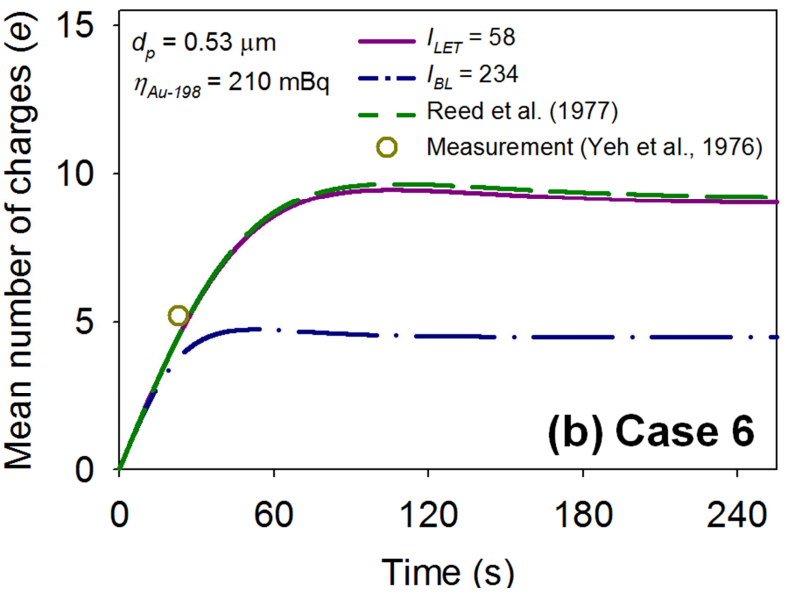

Figure 2. Charge accumulation rate for

Cases 5-7: (a) Case 5, (b) Case 6, and (c) Case 7.

Figure 3 shows charge distributions of ${ }^{137}$ Cs particles containing other radionuclides under the experimental conditions of Cases 1 and 2. The relative difference of charge distributions represents the effects of each radionuclide on charge accumulation rates. The charge distributions of ${ }^{137} \mathrm{Cs}$ particles became quite different as short-lived radionuclides were added.

The contained short-lived radionuclides increased the self-charging rates of the particles, thus accumulating more positive charges. Despite differences in ionization rate coefficients, the ${ }^{137} \mathrm{Cs}$ particles accumulated more positive charges as the half-life of the added radionuclides was much shorter $\left({ }^{132} \mathrm{Te}>{ }^{131} \mathrm{I}>{ }^{134} \mathrm{Cs}\right)$. As more ion pairs were created, the positively charged radioactive particles were effectively neutralized due to the diffusion of more negative ions (Cases 1 vs. 2). 

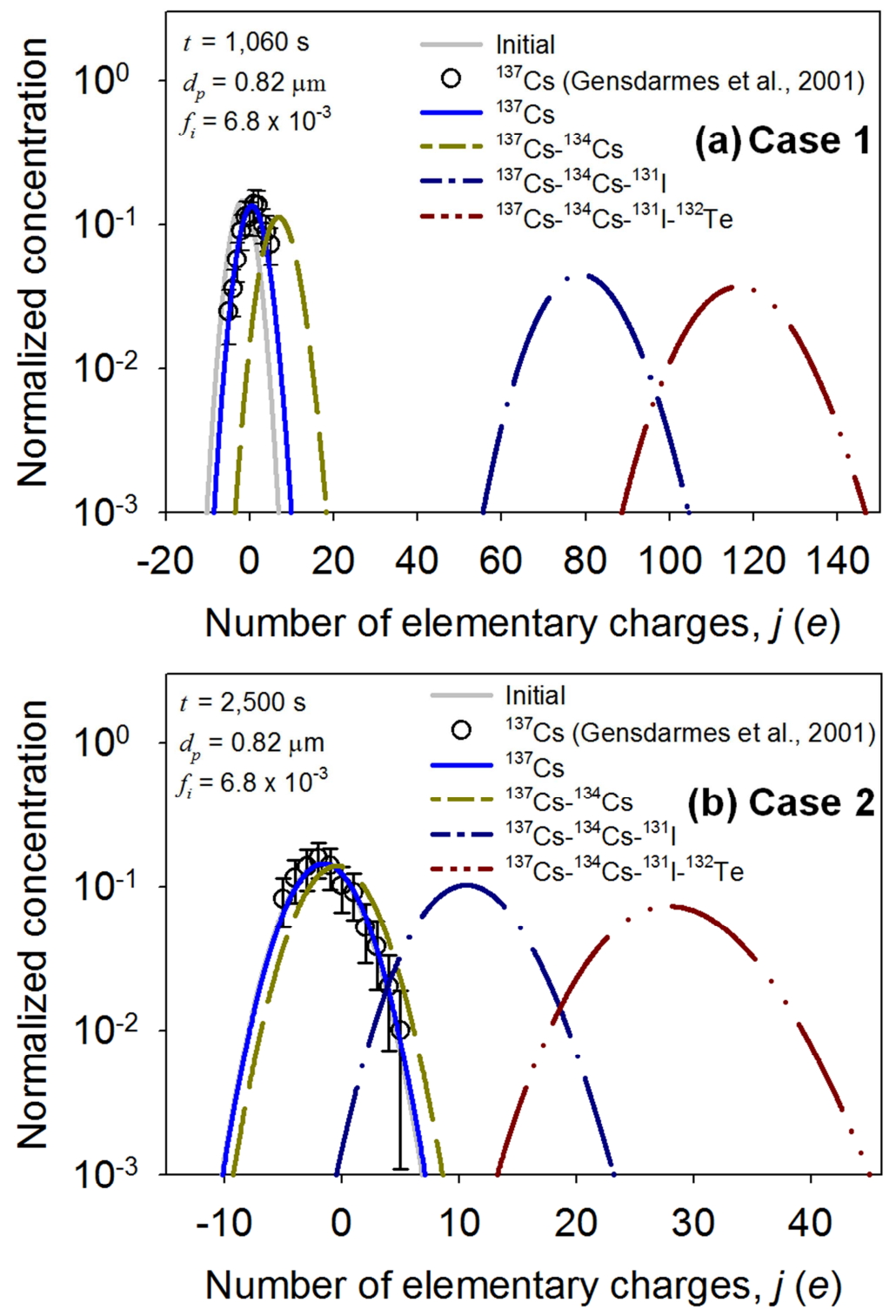

Figure 3. Charge distributions of particles containing short- and long-lived radionuclides: (a) Case 1 and (b) Case 2.

Particles of lower mole fraction of radioactive elements accumulated fewer positive charges, but the effects of the contained short-lived radionuclides persisted (Cases 1 vs. 3 and 2 vs. 4; data not shown). These results suggest that the type, amount, and ionization rate coefficient of radionuclides contained in particles influence significantly charge accumulation on radioactive particles. 


\subsubsection{Ionization Rate Coefficient of Beta-emitting Radionuclides in Dry Air}

223

224

225 dry air.

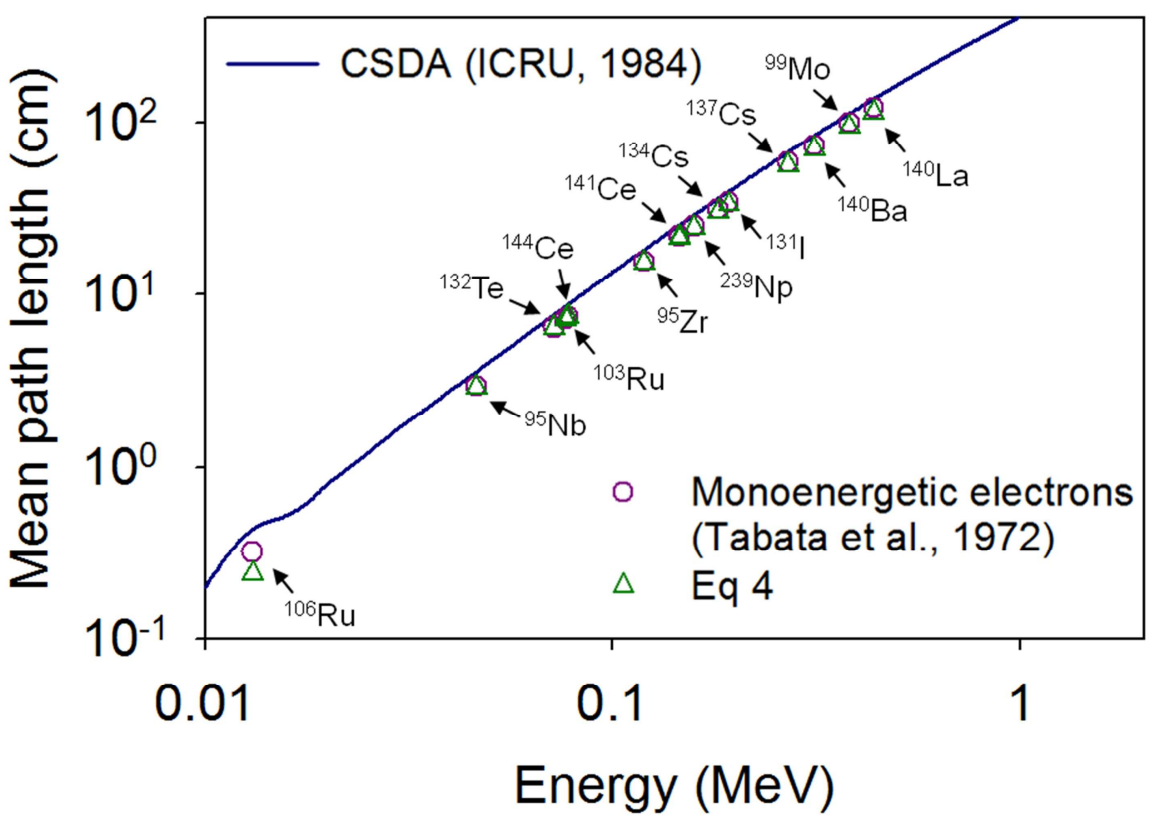

Figure 4. Mean path length of electrons emitted during beta decay of various radionuclides in dry air. 
Table 2 shows the ionization rate coefficient of various beta-emitting radionuclides estimated using the LET approach with the Katz and Penfold relationship.

Table 2. Ionization rate coefficient of various beta-emitting radionuclides in dry air

$($ Temperature $=295 \mathrm{~K}$; Pressure $=100 \mathrm{kPa})$

\begin{tabular}{|c|c|c|c|c|c|}
\hline \multirow{2}{*}{ Radionuclide } & \multirow{2}{*}{ Half-life } & \multicolumn{2}{|c|}{ Energy of electrons $(\mathrm{MeV})$} & \multirow{2}{*}{$\begin{array}{l}\text { Mean path length of } \\
\text { electrons }(\mathrm{cm})\end{array}$} & \multirow{2}{*}{$\begin{array}{l}\text { Ionization rate } \\
\text { coefficient, } I\end{array}$} \\
\hline & & $E_{\max }^{\mathrm{a}}$ & $E_{\text {mean }}^{\mathrm{b}}$ & & \\
\hline${ }^{95} \mathrm{Zr}$ & $64.032 \mathrm{~d}$ & 0.3960 & 0.1191 & 15.35 & 1,261 \\
\hline${ }^{95} \mathrm{Nb}$ & $34.991 \mathrm{~d}$ & 0.1600 & 0.0463 & 2.91 & 472 \\
\hline${ }^{99} \mathrm{Mo}$ & $2.7489 \mathrm{~d}$ & 1.1800 & 0.3803 & 93.93 & 4,323 \\
\hline${ }^{103} \mathrm{Ru}$ & $39.26 \mathrm{~d}$ & 0.2294 & $0.0765^{c}$ & 7.19 & 800 \\
\hline${ }^{106} \mathrm{Ru}$ & $373.59 \mathrm{~d}$ & 0.0394 & $0.0131^{c}$ & 0.24 & 110 \\
\hline${ }^{132} \mathrm{Te}$ & $3.204 \mathrm{~d}$ & 0.2150 & $0.0717^{\mathrm{c}}$ & 6.41 & 748 \\
\hline${ }^{131} \mathrm{I}$ & $8.01 \mathrm{~d}$ & 0.6080 & 0.1812 & 30.43 & 1,945 \\
\hline${ }^{134} \mathrm{Cs}$ & $2.0652 \mathrm{yr}$ & 0.6620 & 0.1581 & 24.45 & 1,688 \\
\hline${ }^{137} \mathrm{Cs}$ & $30.16 \mathrm{yr}$ & 0.5140 & 0.1921 & 33.39 & 2,067 \\
\hline${ }^{140} \mathrm{Ba}$ & $12.752 \mathrm{~d}$ & 1.0200 & 0.2690 & 56.22 & 2,956 \\
\hline${ }^{140} \mathrm{La}$ & $1.6781 \mathrm{~d}$ & 1.3600 & 0.4360 & 114.30 & 5,041 \\
\hline${ }^{141} \mathrm{Ce}$ & $2.508 \mathrm{~d}$ & 0.4350 & 0.1453 & 21.32 & 1,547 \\
\hline${ }^{144} \mathrm{Ce}$ & $284.91 \mathrm{~d}$ & 0.3200 & 0.0778 & 7.41 & 814 \\
\hline${ }^{239} \mathrm{~Np}$ & $2.356 \mathrm{~d}$ & 0.4380 & $0.1460^{c}$ & 21.49 & 1,554 \\
\hline
\end{tabular}

${ }^{\mathrm{a}}$ Mantel (1972) and Martin (2000).

${ }^{\mathrm{b}} E_{\text {mean }}$ of radionuclides was obtained via Mantel (1972) except for ${ }^{103} \mathrm{Ru},{ }^{106} \mathrm{Ru},{ }^{132} \mathrm{Te}$, and ${ }^{239} \mathrm{~Np}$.

${ }^{\mathrm{c}}$ It was assumed that $E_{\text {mean }}=1 / 3 E_{\max }$ (Cooper and Reist, 1973). 


\subsubsection{Charge Distribution of Radioactive Particles in Open Air}

\subsubsection{Testing the Validity of the Assumption of Greenfield (1956)}

Charge accumulation on particles containing radionuclides was investigated under the ionization condition of Greenfield (1956), who showed that up to $75 \%$ of monodispersed radioactive particles $\left(\eta \approx 0.118 \mathrm{~Bq}, I=15,000, N_{t}=3.55 \times 10^{10}\right.$ particles $\left.\mathrm{m}^{-3}\right)$ are neutralized due to beta radiation. Figure 5 shows the steady-state number fraction of the charged and uncharged radioactive particles under the ionization condition of Greenfield (1956): $q_{I}=\eta I N_{t}=6.3 \times 10^{13}$ ion pairs $\mathrm{m}^{-3} \mathrm{~s}^{-1}$. The numbers of the positively and negatively charged particles were similar because of the symmetric particle charge distribution. Despite surface charge neutralization caused by beta radiation, more charged radioactive particles were generated at $250 \mathrm{~K}$ than estimated by Greenfield (1956). A similar result was obtained for $295 \mathrm{~K}$. These discrepancies mainly resulted from the ion-particle attachment coefficient in eqs 6-8. We used the typical values of the ion-particle attachment coefficient in the lower atmosphere (e.g., $\beta_{-1}^{+}=\beta_{+1}^{-}=$ $2.7 \times 10^{-12} \mathrm{~m}^{3} \mathrm{~s}^{-1}$ and $\beta_{0}^{ \pm}=1.5 \times 10^{-12} \mathrm{~m}^{3} \mathrm{~s}^{-1}$ at $250 \mathrm{~K} ; \beta_{-1}^{+}=\beta_{+1}^{-}=3.2 \times 10^{-12} \mathrm{~m}^{3} \mathrm{~s}^{-1}$ and $\beta_{0}^{ \pm}=$ $1.9 \times 10^{-12} \mathrm{~m}^{3} \mathrm{~s}^{-1}$ at $295 \mathrm{~K}$ ), while Greenfield assumed that $\beta_{-1}^{+}=\beta_{+1}^{-}=6 \times 10^{-12} \mathrm{~m}^{3} \mathrm{~s}^{-1}$ and $\beta_{0}^{ \pm}=$ $10^{-12} \mathrm{~m}^{3} \mathrm{~s}^{-1}$ at $250 \mathrm{~K}$. The values of the attachment coefficient estimated by Greenfield are beyond the typical range of values suggested more recently by many researchers (Harrison and Carslaw, 2003; Hoppel and Frick, 1986). The difference in the values of the ion-particle attachment coefficient resulted in dissimilar charge accumulation and neutralization rates of the radioactive particles, leading to the discrepancies mentioned above. The results of this study suggest that many radioactive particles can be charged despite the occurrence of charge neutralization induced by beta radiation in open air. 


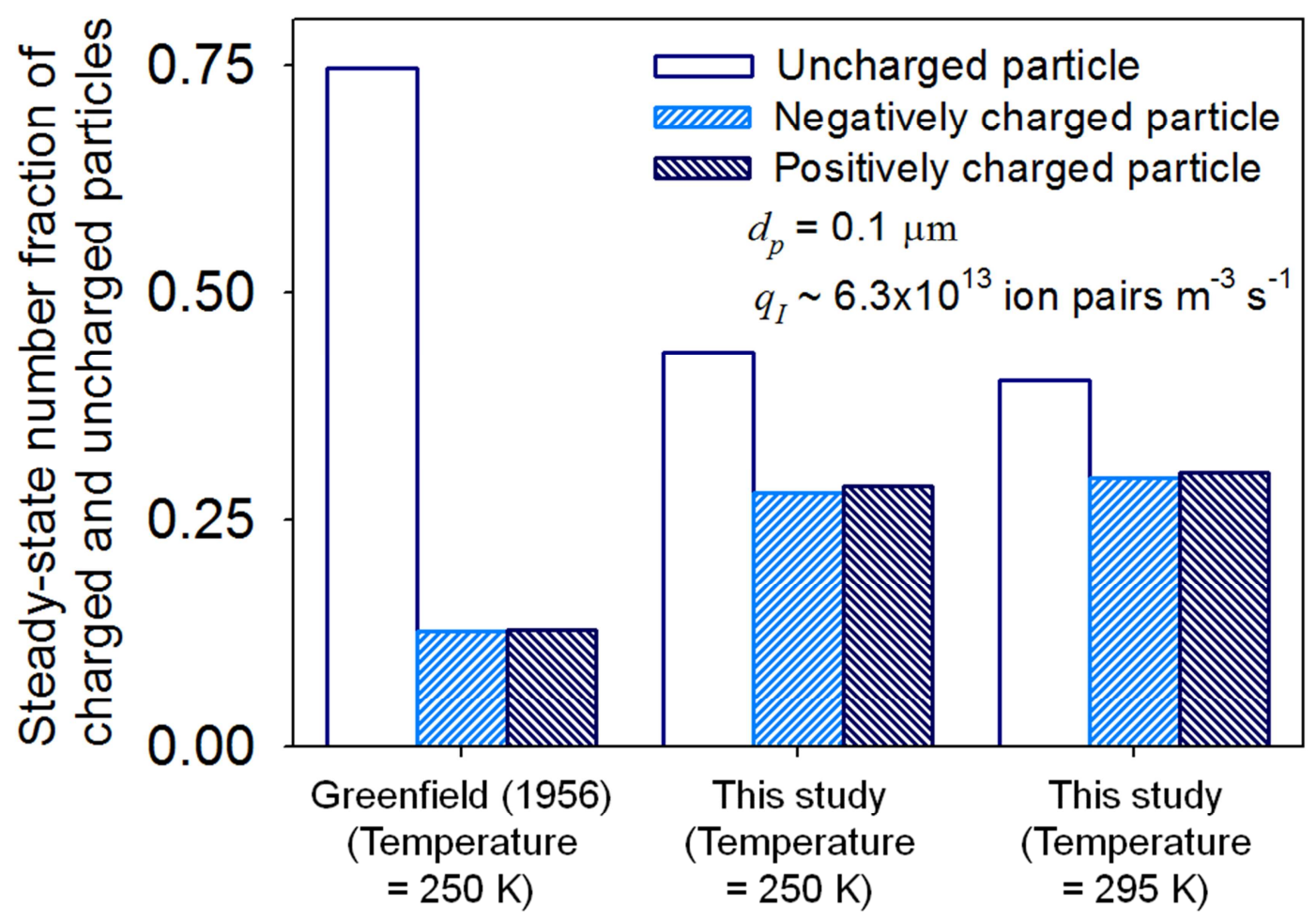

Figure 5. Steady-state number fraction of charged and uncharged radioactive particles under the ionization condition of Greenfield (1956).

\subsubsection{Effects of Radioactive Particles on Particle Charge Distribution in the}

\section{Atmosphere}

The Chernobyl accident released many particles containing beta-emitting radionuclides into the atmosphere. During short- and long-range transport, the radioactive particles became charged and ionized air molecules, thereby affecting the particle charge distribution in the atmosphere. Thus, effects of the Chernobyl radioactive particles on the particle charge distribution in the atmosphere were investigated here, using the charge balance model.

272 For single particle composition, we used observations of Devell et al. (1986) who measured properties of individual Chernobyl radioactive particles. Hereafter, we refer to the radioactive 
particles by Ch1, Ch2, and Ch3: Ch1 contained ${ }^{103} \mathrm{Ru},{ }^{99} \mathrm{Mo},{ }^{106} \mathrm{Ru},{ }^{132} \mathrm{Te}$, and ${ }^{131} \mathrm{I}$; Ch2 involved ${ }^{103} \mathrm{Ru},{ }^{106} \mathrm{Ru},{ }^{132} \mathrm{Te}$, and ${ }^{131} \mathrm{I}$; Ch3 consisted of ${ }^{106} \mathrm{Ru},{ }^{131} \mathrm{I},{ }^{140} \mathrm{Ba},{ }^{140} \mathrm{La},{ }^{95} \mathrm{Zr},{ }^{95} \mathrm{Nb},{ }^{141} \mathrm{Ce},{ }^{144} \mathrm{Ce}$, and ${ }^{239} \mathrm{~Np}$. The radioactivity of each radionuclide was given by Devell et al. (1986). The total radioactivity of $\mathrm{Ch} 1, \mathrm{Ch} 2$, and $\mathrm{Ch} 3$ was $15,280 \mathrm{~Bq}, 8,780 \mathrm{~Bq}$, and 2,740 $\mathrm{Bq}$, respectively. The size distribution of background aerosols (BA) was obtained from Trier (1997). It was assumed that (i) the monodispersed Chernobyl radioactive particles were mixed with BA, (ii) their total particle number concentrations were similar, and (iii) all particles were initially neutralized. The charge balance equation was defined for each particle group and all equations were solved simultaneously. The ionization rate coefficients shown on Table 2 were used to calculate $q_{I, i}$ in eqs 7 and 8. Some typical values used in simulation were obtained from Harrison and Carslaw (2003) by assuming the fair-weather atmosphere (e.g., $q_{b}=10^{7}$ ion pairs $\mathrm{m}^{-3} \mathrm{~s}^{-1}$ and $\alpha_{r c}=$ $1.6 \times 10^{-12} \mathrm{~m}^{3} \mathrm{~s}^{-1}$.)

Figure 6 shows the steady-state particle charge distributions in fair-weather atmosphere involving various Chernobyl radioactive particles. Beta radiation caused by the radioactive particles generated numerous ion pairs in the atmosphere. The ions were rapidly captured by the background aerosols and the particles quickly obtained a unimodal symmetrical charge distribution (i.e., the Boltzmann distribution). However, despite ionization induced by beta radiation, most Chernobyl radioactive particles accumulated more positive than negative charges because of the self-charging mechanism. The presence of the positively charged particles produced asymmetric bimodal particle charge distributions in the atmosphere. When the selfcharging mechanism was neglected, all particle charge distributions became Boltzmann distributions. 


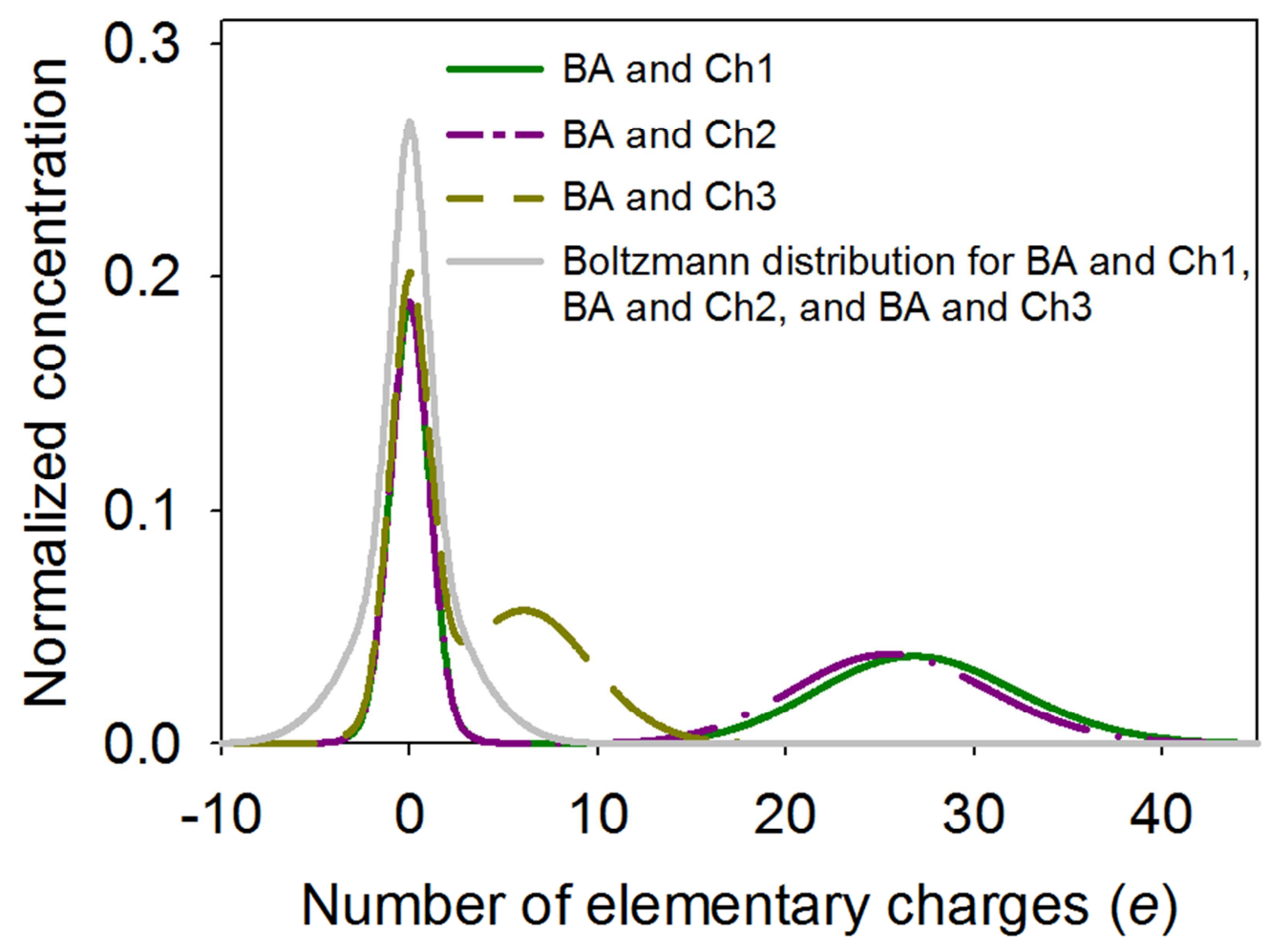

297 Figure 6. Particle charge distributions in fair-weather atmosphere containing various Chernobyl 298 radioactive particles (Ch1, Ch2, and Ch3; $\left.d_{p}=1 \mu \mathrm{m}\right)$. The geometric mean diameter, $d_{g}$ and 299 geometric standard deviation $\sigma_{g}$ of the background aerosols (BA) are $0.116 \mu \mathrm{m}$ and 1.46 , 300 respectively (Trier, 1997). $N_{B A}=N_{C h 1}=N_{C h 2}=N_{C h 3}=6.718 \times 10^{9}$ particles $\mathrm{m}^{-3}$.

The particle charge distributions in fair-weather atmosphere involving radioactive particles were investigated using polydispersed conditions. We assumed ammonium sulfate particles carrying ${ }^{103} \mathrm{Ru},{ }^{99} \mathrm{Mo},{ }^{106} \mathrm{Ru},{ }^{132} \mathrm{Te}$, and ${ }^{131} \mathrm{I}$ which correspond to the radioactive composition of $\mathrm{Ch} 1$. Radioactivity of single particles was calculated using eq 1 . The initial size distribution of polydispersed radioactive particles was obtained from Tripathi and Harrison (2001).

Figure 7 shows the steady-state particle charge distributions in the atmosphere containing the polydispersed radioactive particles. For all cases, the particle charge distribution was different from the Boltzmann distribution. Some particles were highly radioactive and accumulated many 
positive charges until reaching steady state. As the mole fraction of the radionuclides increased, the number of highly radioactive particles increased and thus, more positively charged particles were generated. If the mole fraction of the radionuclides is similar, large particles can contain more radionuclides than small particles (eq 1). Thus, the self-charging rate of single radioactive particles was dissimilar for different-size particles, and this led to the creation of the asymmetric multimodal particle charge distributions in the atmosphere.

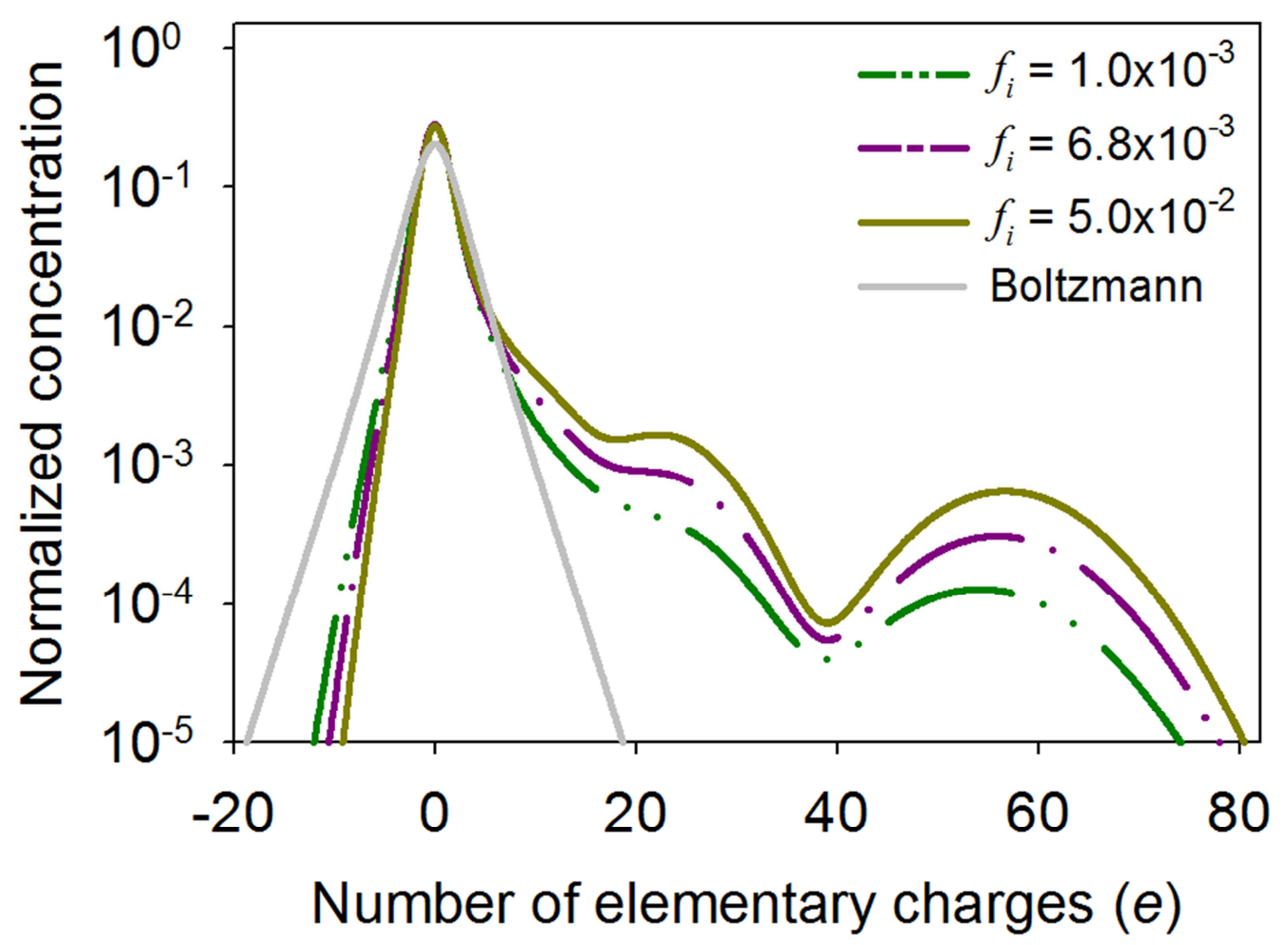

Figure 7. Particle charge distributions in fair-weather atmosphere containing background aerosols and particles containing ${ }^{103} \mathrm{Ru},{ }^{99} \mathrm{Mo},{ }^{106} \mathrm{Ru},{ }^{132} \mathrm{Te}$, and ${ }^{131} \mathrm{I} . d_{g, B A}=0.116 \mu \mathrm{m}, \sigma_{g, B A}=$ $1.46, d_{g, C h l}=0.52 \mu \mathrm{m}, \sigma_{g, C h l}=2.4$, and $N_{B A}=N_{C h l}=6.718 \times 10^{9}$ particles $^{-3}$.

In the simulations, we assumed similar ion mobilities for positive and negative ions, which correspond to those in fair-weather atmosphere (Harrison and Carslaw, 2003), but positive ions 
are typically less mobile than negative ions (Clement and Harrison, 1992; Hoppel and Frick, 1986; Gensdarmes et al., 2001). However, the asymmetric bi- and multi-modal charge distributions created by the Chernobyl radioactive particles were maintained for both equal and unequal ion mobilities of positive and negative ions (data not shown).

In fair-weather atmosphere, where cosmic ray and natural radioactivity are major ionization sources, the time needed to reach a steady-state charge distribution can be delayed due to low ion concentrations (Yair and Levin, 1995), but for all cases, the steady-state particle charge distribution was attained within a few seconds due to the rapid ionization by beta radiation. Thus, other processes, such as aggregation, may not affect the steady-state charge distributions caused by the Chernobyl radioactive particles because of the short simulation time, as well as the low particle concentrations. Effects of aggregation on the particle charge distributions should be evaluated if timescale to reach the steady-state particle charge distributions is long or particle concentrations are high.

These results suggest that radioactive particles can significantly influence the particle charge distributions in the atmosphere during short- and long-range transport.

\subsubsection{Possible Effects of Radioactive Particles on Transport of Radioactivity and Atmospheric Electricity}

Charge accumulation on radioactive particles can significantly influence short- and long-range transport of radioactivity because it induces strong electrostatic interactions. The generation of an asymmetric bimodal particle charge distribution would produce strong electrostatic particle- 
particle interactions, which would greatly affect particle growth (Matsoukas, 1997; Oron and Seinfeld, 1989a, 1989b). For example, positively charged radioactive particles may attract negatively charged background aerosols. Additionally, radioactive particles can favorably interact with raindrops due to the electrostatic image force generated between them. Recent experiments of Walker et al. (2010) suggested that radioactivity increased the adhesion force between a charged particle and a conductive surface through the generation of the attractive image force. Radioactive surfaces can be charged at humid conditions (Kweon et al., 2013) and the surface charge of the particles in the proximity of raindrops can generate an attractive electrostatic image force (Tripathi and Harrison, 2001). Thus, the scavenging rate of charged radioactive particles may be enhanced by radioactivity-induced electrostatic interactions. Hence, the dry and wet deposition rates of radioactive particles may be significantly affected by electrostatic interactions caused by radioactivity.

During atmospheric transport, radioactive particles can significantly influence the electrical properties of the local atmosphere because they can ionize air molecules. Table 3 shows changes in electrical properties of the local atmosphere by radioactive particles measured after nuclear events, including the Chernobyl accident. During short- and long-range transport, radioactive particles were accumulated on ground surfaces via various mechanisms, such as thundershower, and dry and wet deposition. For example, radioactive particles flying at 5-km altitude were carried to ground surfaces by thundershower (Harris, 1955). Ionization induced by the radioactive particles increased ion concentrations near ground surfaces and this led to changes in electrical properties of the local atmosphere. High ion concentrations increased the electrical conductivity of the local atmosphere to much higher than normal levels. This could result in short-circuiting of the electric field (Israelsson and Knudsen, 1986; 1987), thereby decreasing 
potential gradient and space charge in the local atmosphere. The duration time of these effects may depend on radioactivity in air and on ground surfaces because radioactive particles can be

367 transported to other places by various processes, such as runoff (Israelsson and Knudsen, 1986)

368 and wind-driven resuspension (Yamauchi et al., 2012).

Table 3. Changes in electrical properties of the local atmosphere by transported radionuclides.

\begin{tabular}{|c|c|c|c|c|c|c|c|c|}
\hline $\begin{array}{l}\text { Nuclear } \\
\text { events }\end{array}$ & $\begin{array}{l}\text { Emission } \\
\text { sources }\end{array}$ & Observations & $\begin{array}{l}\text { Distance } \\
\text { from } \\
\text { emission } \\
\text { sources }\end{array}$ & $\begin{array}{l}\text { Major transport } \\
\text { mechanisms } \\
\text { (from the local } \\
\text { atmosphere to } \\
\text { ground level) }\end{array}$ & $\begin{array}{l}\text { Electrical } \\
\text { conductivity } \\
\underset{a}{a}\end{array}$ & $\begin{array}{l}\text { Potential } \\
\text { gradient }^{\text {a }}\end{array}$ & $\begin{array}{c}\text { Space } \\
\text { charge }^{\text {a }}\end{array}$ & Reference \\
\hline $\begin{array}{l}\text { Weapon } \\
\text { tests }\end{array}$ & $\begin{array}{l}\text { Nevada, } \\
\text { USA }\end{array}$ & $\begin{array}{l}\text { Tucson, } \\
\text { USA }\end{array}$ & $850 \mathrm{~km}$ & Thundershower & $\begin{array}{l}10 \text { times } \\
\text { increase }\end{array}$ & $\begin{array}{l}6 \text { times } \\
\text { decrease }\end{array}$ & - & $\begin{array}{l}\text { Harris } \\
(1955)\end{array}$ \\
\hline \multirow{5}{*}{$\begin{array}{l}\text { Nuclear } \\
\text { plant } \\
\text { accidents }\end{array}$} & \multirow{3}{*}{$\begin{array}{c}\text { Chernobyl, } \\
\text { Ukraine }\end{array}$} & $\begin{array}{l}\text { Uppsala, } \\
\text { Sweden }\end{array}$ & $1,300 \mathrm{~km}$ & Wet deposition & $\begin{array}{l}11 \text { times } \\
\text { increase }\end{array}$ & $\begin{array}{l}10 \text { times } \\
\text { decrease }\end{array}$ & $\begin{array}{l}10 \text { times } \\
\text { decrease }\end{array}$ & $\begin{array}{c}\text { Israelsson } \\
\text { and Knudsen } \\
(1986)\end{array}$ \\
\hline & & $\begin{array}{l}\text { Athens, } \\
\text { Greece }\end{array}$ & $1,500 \mathrm{~km}$ & Dry deposition & $\begin{array}{l}7 \text { times } \\
\text { increase }\end{array}$ & $\begin{array}{l}2 \text { times } \\
\text { decrease }\end{array}$ & - & $\begin{array}{l}\text { Retalis } \\
\text { and Pitta } \\
(1989)\end{array}$ \\
\hline & & $\begin{array}{l}\text { Vantaa, } \\
\text { Finland }\end{array}$ & $1,050 \mathrm{~km}$ & $\begin{array}{l}\text { Dry and wet } \\
\text { deposition }\end{array}$ & $\begin{array}{l}10 \text { times } \\
\text { increase }\end{array}$ & $\begin{array}{l}10 \text { times } \\
\text { decrease }\end{array}$ & - & $\begin{array}{l}\text { Toumi } \\
\text { (1989) }\end{array}$ \\
\hline & \multirow{2}{*}{$\begin{array}{c}\text { Fukushima, } \\
\text { Japan }\end{array}$} & $\begin{array}{l}\text { Kakioka, } \\
\text { Japan }\end{array}$ & $150 \mathrm{~km}$ & $\begin{array}{l}\text { Dry and wet } \\
\text { deposition }\end{array}$ & - & $\begin{array}{l}10 \text { times } \\
\text { decrease }\end{array}$ & - & $\begin{array}{l}\text { Takeda et al. } \\
\quad(2011)\end{array}$ \\
\hline & & $\begin{array}{l}\text { Kakioka, } \\
\text { Japan }\end{array}$ & $150 \mathrm{~km}$ & $\begin{array}{l}\text { Dry and wet } \\
\text { deposition } \\
\text { Resuspension }\end{array}$ & - & $\begin{array}{l}10 \text { times } \\
\text { decrease }\end{array}$ & - & $\begin{array}{l}\text { Yamauchi et } \\
\text { al. (2012) }\end{array}$ \\
\hline
\end{tabular}

$\overline{{ }^{a}}$ Changes in electrical properties were obtained by comparing maximum values for observations with normal levels of observation locations. 
After the Chernobyl accident, abnormal lightning activity was observed at contaminated radioactive sites in Sweden (Israelsson and Knudsen, 1987). Lightning flashes of the contaminated sites significantly increased for a few months after the accident. The average lightning frequency of the contaminated sites was up to five times higher than that of lowradioactivity sites. Israelsson and Knudsen (1987) suggested that the observations of lightning activity enhancement may be attributed to ionization caused by radioactivity.

\section{Conclusions}

In case of a nuclear plant accident, accurate prediction of radioactivity transport is crucial in evaluating environmental and health risks caused by radioactive contamination. Electrostatic interactions can be important in simulating various atmospheric processes, but they are typically neglected in modeling studies of radioactivity transport. This study has shown that radioactivity can induce surface charge accumulation of radioactive particles and background aerosols, significantly influence the particle charge distribution in open air, and change the electrical properties of the local atmosphere. Based on the charging behavior of radioactive particles and the expected influence of radioactivity-induced charge on particle interactions with other particles, raindrops, and other environmental surfaces, electrostatic interactions should be considered in predictive studies of short- and long-range radioactivity transport.

ACKNOWLEDGMENTS. This work was supported by the Defense Threat Reduction Agency under grant number DTRA1-08-10-BRCWMD-BAA. The manuscript has been co-authored by UT-Battelle, LLC, under Contract No. DEAC05-00OR22725 with the U.S. Department of Energy. 


\section{REFERENCES}

ApSimon, H., Wilson, J. J. N., Simms, K. L., 1989. Analysis of the dispersal and deposition of radionuclides from Chernobly across Europe. Proc. R. Soc. A 425, 365-405.

Bragg, W. H., Kleeman, R., 1905. XXXIX. On the $\alpha$ particles of radium, and their loss of range in passing through various atoms and molecules. Philos. Mag. 10, 318-340.

Chesser, R.K., Bondarkov, M., Baker, R.J., Wickliffe, J.K., Rodgers, B.E., 2004. Reconstruction of radioactive plume characteristics along Chernobyl's Western trace. J. Environ. Radioactivity 71, 147-157.

Clement, C. F., Harrison, R. G., 1992. The charging of radioactive aerosols. J. Aerosol Sci. 23, 481-504.

Cooper, D. W., Reist, P. C., 1973. Neutralizing charged aerosols with radioactive sources. J. Colloid Interface Sci. 45, 17-26.

Cuddihy, R. G., Finch, G. L., Newton, G. J., Hahn, F. F., Mewhinney, J. A., Rothenberg, S. J., Powers, D. A., 1989. Characteristics of radioactive particles released from the Chernobyl nuclear reactor. Environ. Sci. Technol. 23, 89-95.

Devell, L., Tovedal, H., Bergström, U., Appelgren, A. 1., Chyssler, J., Andersson, L., 1986. Initial observations of fallout from the reactor accident at Chernobyl. Nature 321, 192193.

Gensdarmes, F., Boulaud, D., Renoux, A., 2001. Electrical charging of radioactive aerosolscomparison of the Clement-Harrison models with new experiments. J. Aerosol Sci. 32, $1437-1458$.

Greenfield, S. M., 1956. Ionization of radioactive particles in the free air. J. Geophys. Res. 61, 27-33. 
Greenfield, S. M., 1957. Rain scavenging of radioactive particulate matter from the atmosphere. J. Atmos. Sci. 14, 115-125.

Harrison, R. G., Carslaw, K. S., 2003. Ion-aerosol-cloud processes in the lower atmosphere. Rev. Geophys. 41, 1012.

Hoppel, W. A., Frick, G. M., 1986. Ion-aerosol attachment coefficients and the steady-state charge distribution on aerosols in a bipolar ion environment. Aerosol Sci. Technol. 5, 121.

Huizenga, H., Storchi, P. R. M., 1989. Numerical calculation of energy deposition by broad high-energy electron beams. Phys. Med. Biol. 34, 1371-1396.

International Commission on Radiation Units and Measurements (ICRU), 1984. Stopping powers for electrons and positrons, ICRU Report 37, ICRU, Bethesda, M. D.

Israelsson, S., Knudsen, E., 1986. Effects of radioactive fallout from a nuclear power plant accident on electrical parameters. J. Geophys. Res. 91, 11909-11910.

Israelsson, S., Schütte, T., Pisler, E., Lundquist, S., 1987. Increased occurrence of lightning flashes in Sweden during 1986. J. Geophys. Res. 92, 10996-10998.

Joffre, H., 1963. Les Problèmes physiques de la radioprotection; Institut national des sciences et techniques nucléaires, Paris, France.

Kaneyasu, N., Ohashi, H., Suzuki, F., Okuda, T., Ikemori, F., 2012. Sulfate aerosol as a potential transport medium of radiocesium from the Fukushima nuclear accident. Environ. Sci. Technol. 46, 5720-5726.

Kauppinen, E. I., Hillamo, R. E., Aaltonen, S. H., Sinkko, K. T. S., 1986. Radioactivity size distributions of ambient aerosols in Helsinki, Finland, during May 1986 after the Chernobyl accident: preliminary report. Environ. Sci. Technol. 20, 1257-1259. 
Katz, L, Penfold, A. S., 1952. Range-energy relations for electrons and the determination of beta-ray end-point energies by absorption. Rev. Mod. Phys. 24, 28-44.

Kim, Y.-H., Yiacoumi, S., Lee, I., McFarlane, J., Tsouris, C., 2014. Influence of radioactivity on surface charging and aggregation kinetics of particles in the atmosphere. Environ. Sci. Technol. 48, 182-189.

Kweon, H., Yiacoumi, S., Lee, I., McFarlane, J., Tsouris, C., 2013. Influence of surface potential on the adhesive force of radioactive gold surfaces. Langmuir 29, 11876-11883.

Lee, H., Feichter, J., 1995. An intercomparison of wet precipitation scavenging schemes and the emission rates of $222 \mathrm{Rn}$ for the simulation of global transport and deposition of $210 \mathrm{~Pb}$. J. Geophys. Res.-Atmos. 100, 23253-23270.

Harris, D. L., 1955. Effects of radioactive debris from nuclear explosions on the electrical conductivity of the lower atmosphere. J. Geophys. Res. 60, 45-52.

Lujanienè, G., Aninkevičius, V., Lujanas, V., 2009. Artificial radionuclides in the atmosphere over Lithuania. J. Environ. Radioactiv., 100, 108-119.

Mantel, J., 1972. The beta ray spectrum and the average beta energy of several isotopes of interest in medicine and biology. Int. J. Appl. Radiat. Is. 23, 407-413.

Marmier, P., Sheldon, E., 1969. Physics of Nuclei and Particles (Volume I), Academic Press, New York.

Martin, J. E., 2000. Physics for Radiation Protection, John Wiley \& Sons, New York.

Matsoukas, T., 1997. The coagulation rate of charged aerosols in ionized gases. J. Colloid Interface Sci. 187, 474-483.

Ooe, H., Seki, R., Ikeda, N., 1988. Particle-size distribution of fission products in airborne dust collected at Tsukuba from April to June 1986. J. Environ. Radioactivity 6, 219-223. 
Oron, A., Seinfeld, J. H., 1989a. The dynamic behavior of charged aerosols: II. Numerical solution by the sectional method. J. Colloid Interface Sci. 133, 66-79.

Oron, A., Seinfeld, J. H., 1989b. The dynamic behavior of charged aerosols: III. Simultaneous charging and coagulation. J. Colloid Interface Sci. 133, 80-90.

Parache, V., Pourcelot, L., Roussel-Debet, S., Orjollet, D., Leblanc, F., Soria, C., Gurriaran, R., Renaud, P., Masson, O., 2011. Transfer of ${ }^{131}$ I from Fukushima to the vegetation and milk in France. Environ. Sci. Technol. 45, 9998-10003.

Pöllänen, R., Valkama, I., Toivonen, H., 1997. Transport of radioactive particles from the Chernobyl accident. Atmos. Environ. 31, 3575-3590.

Reed, L. D., Jordan, H., Gieseke, J. A., 1977. Charging of radioactive aerosols. J. Aerosol Sci. 8, 457-463.

Rehfeld, S., Heimann, M., 1995. Three dimensional atmospheric transport simulation of the radioactive tracers $210 \mathrm{~Pb}, 7 \mathrm{Be}, 10 \mathrm{Be}$, and $90 \mathrm{Sr}$. J. Geophys. Res.-Atmos. 100, 26141 26161.

Renard, J. B., Tripathi, S. N., Michael, M., Rawal, A., Berthet, G., Fullekrug, M., Harrison, R. G., Robert, C., Tagger, M., Gaubicher, B., 2013. In situ detection of electrified aerosols in the upper troposphere and in the stratosphere. Atmos. Chem. Phys. 13, 11187-11194.

Retalis, D., Pitta, A., 1989. Effects on electrical parameters at Athens, Greece by radioactive fallout from a nuclear power plant accident. J. Geophys. Res. 94, 13093-13097.

Seinfeld, J. H., Pandis, S.N., 2006. Atmospheric Chemistry and Physics: From Air Pollution to Climate Change, John Wiley and Sons, New Jersey.

Seltzer, S. M., Berger, M. J., 1982. Evaluation of the collision stopping power of elements and compounds for electrons and positrons. Int. J. Appl. Radiat. Is. 31, 1189-1218. 
Shaw, G. E., 1986. Size distribution of atmospheric aerosols at Ross Island. Antarct. J. U.S. 21, 241-242.

Tabata, T., Ito, R., Okabe, S., 1972. Generalized semiempirical equations for the extrapolated range of electrons. Nucl. Instrum. Methods 103, 85-91.

Takeda, M., Yamauchi, M., Makino, M., Owada, T., 2011. Initial effect of the Fukushima accident on atmospheric electricity. Geophys. Res. Lett., 38, L15811.

Tomé, W. A., Palta, J. R., 1998. On the calculation of mean restricted collision stopping powers. Med. Phys. 25, 758-772.

Trier, A., 1997. Submicron particles in an urban atmosphere: a study of optical size distributions-I. Atmos. Environ. 31, 909-914.

Tripathi, S., Harrison R. G., 2001. Scavenging of electrified radioactive aerosol. Atmos. Environ. $35,5817-5821$.

Walker, M. E., McFarlane, J., Glasgow, D. C., Chung, E., Taboada-Serrano, P., Yiacoumi, S., Tsouris, C., 2010. Influence of radioactivity on surface interaction forces. J. Colloid Interface Sci. 350, 595-598.

Whyte, G., 1963. Energy per ion pair for charged particles in gases. Radiat. Res., 18, 265-271.

Yair, Y., Levin, Z., 1995. Charging of polydispersed aerosol particles by attachment of atmospheric ions. J. Geophys. Res.-Atmos. 94, 13085-13091.

Yamauchi, M., Takeda, M., Makino, M., Owada, T., Miyagi, I., 2012. Settlement process of radioactive dust to the ground inferred from the atmospheric electric field measurement. Ann. Geophys. 30, 49-56. 
506 Yeh, H. C., Newton, G. J., Raabe, O. G., Boor, D. R., 1976. Self-charging of ${ }^{198}$ Au-labeled monodisperse gold aerosols studied with a miniature electrical mobility spectrometer. J. Aerosol Sci. 7, 245-253.

509

510

511

Yoshenko, V.I., Kashparov, V.A., Protsak, V.P., Lundin, S.M., Levchuk, S.E., Kadygrib, A.M., Zvarich, S.I., Khomutinin, X.V., Maloshtan, I.M., Lanshin, V.P., Kovtun, M.V., Tschiervsch, J., 2006a. Resuspension and redistribution of radionucleotides during grassland and forest fires in the Chernobyl exclusion zone. Part I: fire experiments. J. Environ. Radioactivity 86, 143-163.

Yoshenko, V.I. Kashparov, V.A., Levchuk, S.E., Glukhovskiy, A.S,. Khomutni, Y.V., Protsak, V.P., Lundin, S.M., Tschiersch, J., 2006b. Resuspension and redistribution of radionucleotides during grassland and forest fires in the Chernobyl exclusion zone. Part II: modeling the transport process. J. Environ. Radioactivity 87, 260-278. 